\title{
Numerical and Experimental Investigations of Steady Micro-Tip Injection on a Subsonic Axial-Flow Compressor Rotor
}

\author{
Xingen Lu, ${ }^{1}$ Wuli Chu, ${ }^{1}$ Junqiang $\mathrm{Zhu}{ }^{2}$ and Zhiting Tong ${ }^{2}$ \\ ${ }^{1}$ School of Power and Energy, Northwestern Polytechnical University, Xi'an 710072, China \\ ${ }^{2}$ Institute of Engineering Thermophysics, Chinese Academy of Sciences, Beijing 10080, China
}

Received 28 February 2006; Revised 9 July 2006; Accepted 14 July 2006

Steady tip injection has been demonstrated to be an effective means of extending the stable operating range of a tip-critical compressor. This study presents a state-of-the-art design for the tip injection through the casing with flush-mounted inclined holes and the effectiveness of steady micro-air injection to enhance stability in a subsonic axial-flow compressor rotor using an external-air supply. For the tested rotor, experimental results demonstrate that at 53\% design speed, the stalling mass flow can be reduced by $7.69 \%$ using an injected mass flow equivalent to $0.064 \%$ of the annulus flow. Time-dependent CFD simulations were conducted to identify the physical mechanic that accounts for the beneficial effects of the steady micro-air injection on the performance and stability of the compressor. Detailed analyses of the flow visualization at the tip have exposed the different tip flow topologies between the cases without tip injection and with tip injection. It was found that the primary stall margin enhancement afforded by the steady micro-air injection is a result of the tip-clearance flow manipulation. The repositioning of the tip-clearance vortex further towards the trailing edge of the blade passage and delaying the movement of incoming/tip-clearance flow interface to the leading edge plane are the physical mechanisms responsible for extending the compressor stall margin.

Copyright (c) 2006 Xingen Lu et al. This is an open access article distributed under the Creative Commons Attribution License, which permits unrestricted use, distribution, and reproduction in any medium, provided the original work is properly cited.

\section{INTRODUCTION}

Adequate stability is an important feature of any compressor design. The desire to reduce compressor size, weight, and complexity by reducing the number of stages and eliminating variable vanes leads to higher loading per stage, which tends to reduce the stable operating range of compressors. The safe operating range of a gas turbine compressor is limited by the onset of dynamic instabilities of the fluid at low mass flow rates. The two classes of instabilities, rotating stall and surge, can cause unsteady stresses in the compressor blades and reduce the compressor performance. Sustained operation with rotating stall can also lead to excessively high turbine temperatures due to the decreased mass flow through the engine. Typically, the peak pressure rise and peak efficiency of a compressor are located close to the stability boundary. To provide adequate stall margin, the compressor may operate away from the optimum efficiency point. For these reasons, there has been a fairly constant activity over the last decade devoted to the early detection of compressor instability and to the development of active and passive techniques aimed at broadening the compressor operating range.
Perhaps one of the most successful techniques alleviating the stall/surge phenomena is the different configuration of casing treatment means such as slots or grooves over a rotor blade tip [1-4]. Unfortunately, most of the suggested and investigated casing treatment configurations cause a significant drop in efficiency. Fujita and Takata [3] showed that there is almost a linear relation between the stall margin improvement and the rotor maximum efficiency for various types of casing treatments tested. In other words, the general trend is that the more effective a casing treatment configuration is in stall margin improvement, the larger the penalty in compressor efficiency is.

Mass injection upstream of the tip of axial compressor rotor is a stability-enhancement approach known to be effective in suppressing stall in tip-critical rotors [5-9], the design principle of the injection could be either active or passive and the injection can be done in a number of ways. All of them have been demonstrated to be effective in extending the stable operating range of compressors. Compared to steady tip injection, active injection has been demonstrated to provide additional stall margin. Nevertheless, results showed that the total stability improvement is mostly due to steady 


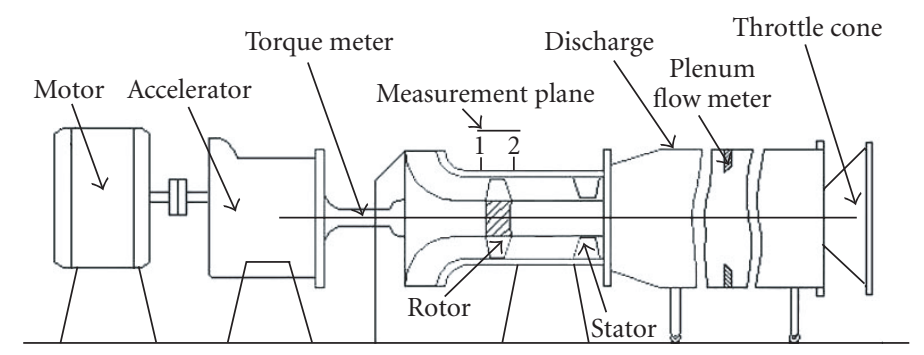

FIGURE 1: Schematic diagram of test compressor facility.

tip injection [5]. In the present effort, the injected flow is supplied from an external source, but this flow should be bled from the rear of the compressor in actual application. Since bleed extraction incurs a cycle penalty due to work done on the injected air [8], there is a strong incentive to minimize the amount of injected mass flow. Based on the above-mentioned argument, a new approach, steady microair injection, was proposed to improve the stability of a lowspeed axial-flow compressor in [10].

Despite much efforts and achievements on mass injection upstream of the tip of axial compressor, several topics should still be very interesting. (1) For a low-speed compressor, experimental results showed that the injected flow of only $0.05 \%$ of the compressor main flow is able to lower the mass flow rate at stall for up to 5.8\% [10]. However, the effectiveness of steady micro-air injection and its effects on the performance of a high-speed compressor need detailed examination. (2) Lack of in-depth understanding of the fluid dynamic processes responsible for the influence brought about by steady micro-air injection [11, 12], the coupled flow through the compressor rotor and injector have been numerically studied. Most previous numerical works have not been anchored with experimental data to show that the simulations are valid, nor have the simulations been advanced enough to describe the details of the flows in the casing area and rotor tips.

This paper presents a state-of-the-art design for the tip injection through the casing with flush-mounted inclined holes. The effect of steady micro-tip injection on compressor's performance and its physical mechanisms which account for beneficial effects of the steady micro-tip injection on the performance and stability were investigated with the help of a high-speed design subsonic compressor test rig tested at part speed subsonic conditions and NUMECA software.

\section{EXPERIMENTAL FACILITY AND INSTRUMENTATION}

The compressor used in this investigation is the first rotor in a single-stage compressor that has been used extensively in previous research programs $[4,9,13]$. The aerodynamic and aeromechanical characteristics of this compressor are well documented with an extensive database of experimental measurements. Figure 1 shows a cross-sectional diagram of the compressor research rig. It consists of a DC motor
TABLE 1: Design specifications of compressor rotor.

\begin{tabular}{lc}
\hline Corrected mass flow $(\mathrm{kg} / \mathrm{s})$ & 5.6 \\
Total-to-total pressure ratio & 1.249 \\
Inlet relative Mach number at tip & 0.78 \\
Shaft speed $(\mathrm{rpm})$ & 12500 \\
Corrected tip speed $(\mathrm{m} / \mathrm{s})$ & 237 \\
Number of blades & 30 \\
Rotor tip diameter $(\mathrm{mm})$ & 298 \\
Hub-tip ratio & 0.61 \\
Nominal tip clearance $(\mathrm{mm})$ & 0.3 \\
Mean aspect ratio & 0.94 \\
Solidity (mid/tip) & $1.165 / 0.96$ \\
\hline
\end{tabular}

$(250 \mathrm{KW})$, an accelerator or gearbox, a torque meter, a test section, an orifice plate flow meter, a discharge duct, and a throttle cone.

The test compressor rotor was isolated from the stator to avoid interaction effects generated by the presence of a downstream stator blade row. The main design specifications of the compressor rotor are presented in Table 1. Previous work indicates that the tested compressor is prone to tip stall behavior, for this reason, upstream injection is particularly suitable.

Rotor performance was usually measured in terms of its total pressure ratio, isentropic efficiency, and mass flow. The performance characteristics of the rotor were acquired using conventional static pressure and total pressure/temperature aerodynamic probes, which were traversed radially approximately $50 \%$ axial-chord upstream of the rotor and $40 \%$ axialchord downstream of the rotor. The probe measurements are corrected for Mach number and streamline slope based on a calibration of each probe used and on the design streamline slope. Radial distributions of total temperature are mass averaged across the annulus. Radial distributions of total pressure are energy averaged by converting them to their enthalpy equivalents and then mass averaging across the annulus. Shaft speed and torque are measured by a torque meter device and the temperature rise was derived from the torque measurement, the compressor rotor mass flow was measured using a calibrated orifice plate installed in the discharge plenum. Mass flow rate through the rotor can be varied by linear movement of a cone at the end of the constant 


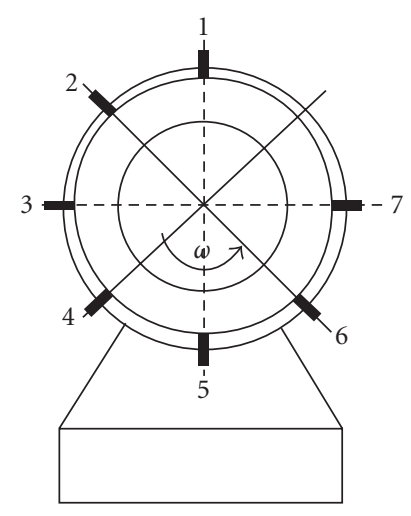

FIgURE 2: Circumferential transducer locations.

area duct as shown in Figure 1. The measurement uncertainties are mass flow, $\pm 0.1 \mathrm{~kg} / \mathrm{s}$; total pressure, $\pm 100 \mathrm{~N} / \mathrm{m}^{2}$. Errors in calculated efficiency are estimated at $\pm 0.2 \%$ maximum, as far as relative comparison between the results for each case is concerned. The stability limit was readily detected audibly as well as on pressure measuring instrumentation which indicated considerable unsteadiness. The limiting flow rates indicated are the "last" stable point that could be obtained before this instability. These conditions repeated within $1 \%$ of flow rate.

In addition to the above-mentioned conventional instrumentation, seven pressure transducers (Kulite XCS -190) were distributed around the casing wall in front of the rotor to detect pressure fluctuations during instability onset and to identify different types of instabilities. The circumferential locations of pressure transducers 1 through 7 are illustrated in Figure 2. These sensors are spaced 45 degree apart between each sensor pair and 90 degrees apart between sensors 1 and 7.

\section{NUMERICAL METHOD}

Computation was done for three-dimensional flow using the Navier-Stokes solver EURANUS [14]. The Favre-Reynoldsaveraged Navier-Stokes equations are discretized using a cellcentered explicit finite volume scheme according to Jameson in a relative coordinate system rotating with the reference frame. The steady-state flow solution is achieved at the convergence of a 4-stage explicit Runge-Kutta integration scheme. The time-marching algorithm is stabilized using scalar eigenvalue-based second- and fourth-order difference smoothing operators. In order to speed up convergence to steady state, local time stepping, residual smoothing and multigrid techniques were applied. The algebraic BaldwinLomax turbulence model was used to introduce turbulence. Time-dependent calculations were implemented in the implicit dual time-stepping scheme, allowing for the solution of a steady-state problem at each physical time step. This methodology retains the main advantages of the explicit

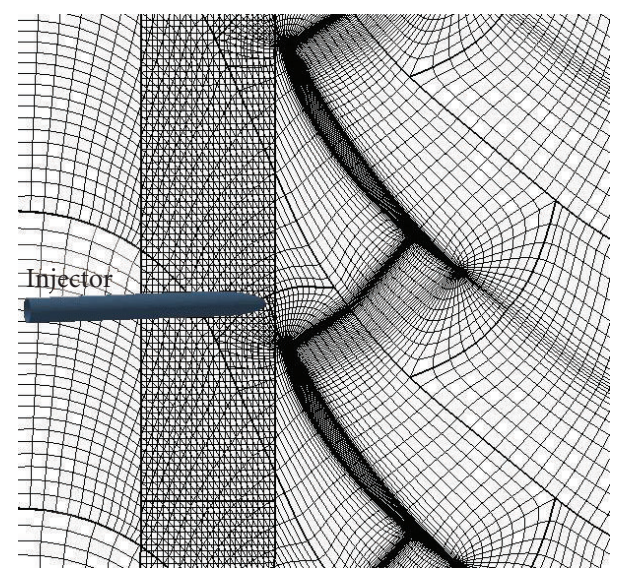

FIGURE 3: Computation grid on the sliding plane between injector and rotor.

time integration scheme already implemented for resolving steady-state problems, as well as retaining local time stepping and implicit residual smoothing. For the time-dependent simulation, 40 physical time steps per blade passage and 20 pseudotime iterations with a CFL number of 2-3 within each physical time step were performed.

There are 4 injectors uniformly spaced around the compressor annulus upstream of the rotor tip in the experiment. However, this work solves only two injectors and fifty blade passages based on the periodicity of the flow field. In this case, the space and time flow periodicities of the flow field are uncoupled and the unsteady flow field may be resolved without having to consider any time periodicity in the boundary treatment. For the prediction of coupled flow through the injector and compressor rotor, block-structured grids are generated independently for the rotor blade passage, the tipclearance region, and the injector. Figure 3 presents a bladeto-blade view of the grids at the zonal interface where the injector is visible. A block-structured topology consisting of I-blocks for the inlet and outlet and a main O-block (surrounding the rotor blade) was used to model the rotor blade passage. The tip gap is gridded with an $\mathrm{H}$-grid embedded into an $\mathrm{O}$-grid. The nonrotating grids of the injectors are "mounted" on a very thin circumferentially closed base (10 percent of the tip-clearance) and linked to the moving rotor passage by an unsteady rotor-stator interface using a sliding plane directly at the casing. Flow data was transferred from the blade passage to injectors using a time-space interpolation procedure, which was equivalent to an interblade row interface in a rotor/stator aerodynamic interaction analysis for multistage turbomachinery, the whole grid system had 3663520 cells.

To evaluate properly the viscous fluxes at the walls using the chosen boundary conditions (no-slip, adiabatic wall condition without a wall function method), the distance away from the wall of the first node had to be judiciously determined. This became an important grid parameter. In this work, the grids were designed such that the maximum distance between the wall and the first node was set such that $y+$ 
was equal or smaller than 2 . The meshing used proved to produce grid-independent results in steady-state simulations. So far, no detailed-grid refinement studies have been carried out for the unsteady case due to massive computing time requirements. However, the authors believe that this meshing is suitable for unsteady simulations as well.

No-slip and no-heat transfer conditions were imposed at solid boundaries. At the inflow boundary of the rotor, flow angle, total pressure and total temperature were prescribed according to the experimental data. At the injector inlet boundary, the speed of injected flow was given the same as in the test case and uniform velocity across the injector exit is assumed. At the subsonic outlet, static pressure was prescribed at the hub and its radial variation was calculated based on the radial equilibrium equation.

\section{THE DESIGN OF INJECTOR AND AIR INJECTION SYSTEM}

Different methods of injection through nozzles inserted into the main flow have been studied previously, however inserting an intrusive element in the main flow field will cause disturbances and is restrictive for application in multistage compressors. Injection through flush-mounted nozzles on the casing before the rotor blades is of more practical utility because of the noninterference of the nozzles with the main flow and adjacent blade. Therefore the first phase of the present effort focused on the design of compact injectors. Based on previous work [15], a new approach, steady micro-air injection form the casing as a variation of casing treatment, is proposed. Schematic diagram of this new injector was shown in Figure 4 (in a radial plane), casing has 4 injectors symmetrically distributed around the compressor annulus $2 \mathrm{~mm}$ (about $11 \%$ of rotor tip axial chord) before the rotor's leading edge. In order to minimize mixing loss between the annulus flow and the injected flow, the injected flow should be aligned with the inlet annulus flow in the downstream axial direction. However, injection holes were inclined 15 degrees to the casing inner surface for injection in a radial plane because of manufacturing limitations. In the stationary frame, air injection is parallel to the axis of rotation. In another word, injection is pointed towards the blade passage direction rather than to the rotation axis, when viewed in the rotating frame.

Air injection was done through a common pipe from the compressor at two different symmetric locations to ensure symmetric flow and all holes were connected through plastic tubes fixed on brass. The injection air is supplied from an external injection system shown in Figure 5, which includes air compressor, air tank, manometer, control valve, flow meter, and the injectors. The flow meter specially chosen for the micro-flow rate is of thin-plate orifice type. Only steady micro-air injection was used in these experiments, the injection flow rate was about $0.064 \%$ of the design mass flow of the compressor rotor, which was controlled by opening a valve in the present work. In a multistage compressor, the injected air should be bled from the rear of the compressor in actual application. Assuming no losses in the recirculation

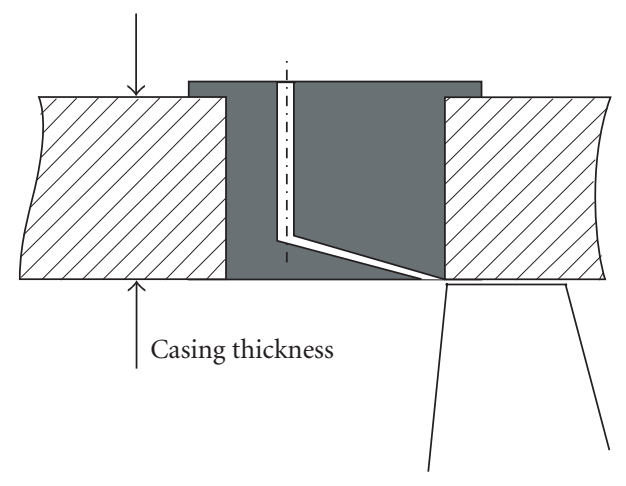

FIgURE 4: Schematic of injection characteristics.

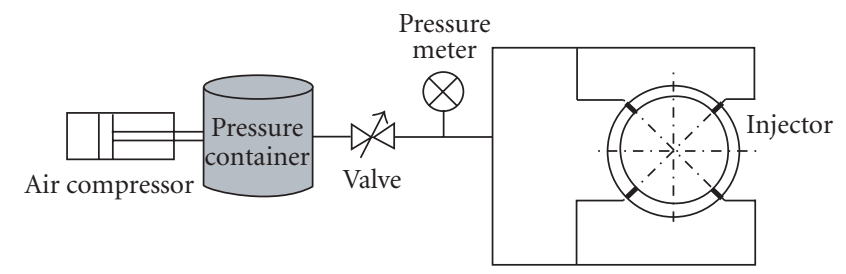

FIGURE 5: Schematic of injection system.

system, this injected flow rate requires that the bleed static pressure be roughly 1.1 times the static pressure at the injection location.

\section{EXPERIMENTAL RESULTS AND DISCUSSION}

The effect of the steady micro-tip injection was investigated by applying it to a single-stage axial-flow compressor, but as a starting point was actually tested on the isolated rotor, with the rear stator removed. The experiments were completed at $33 \%$ and $53 \%$ of the design rotating speed. So far, the compressor was not operated at higher speed because of mechanical concerns. Figure 6 shows the impact of steady micro-tip injection on the stability limit of the axial-flow compressor rotor. Total pressure ratio and isentropic efficiency are plotted as functions of mass flow. So far, the rotor efficiency has not accounted for the introduction of injected mass flow. However, a proper control volume analysis of the computed results has been conducted and it was found that the rotor efficiency almost keeps unchanged with proper consideration injected mass flow crossing the control volume, this may be because the injected mass flow rate is much smaller than the compressor flow rate. The test results confirmed that the steady micro-tip injection had an encouraging impact on the compressor performance and stability. It is clear from the figures that steady micro-tip injection can improve stall margin and isentropic efficiency through the mass flow range and 


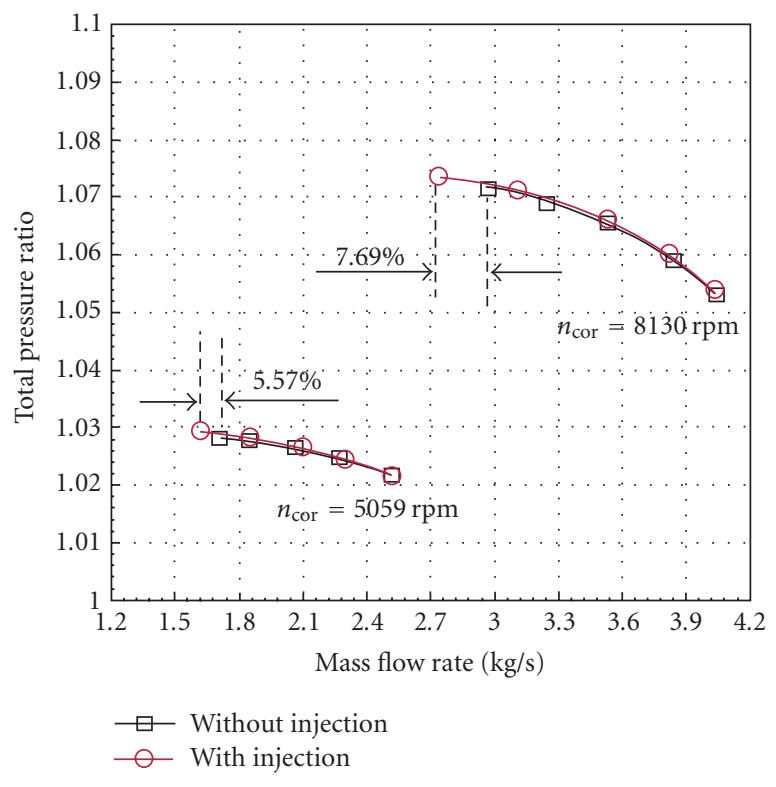

(a) Total pressure ratio

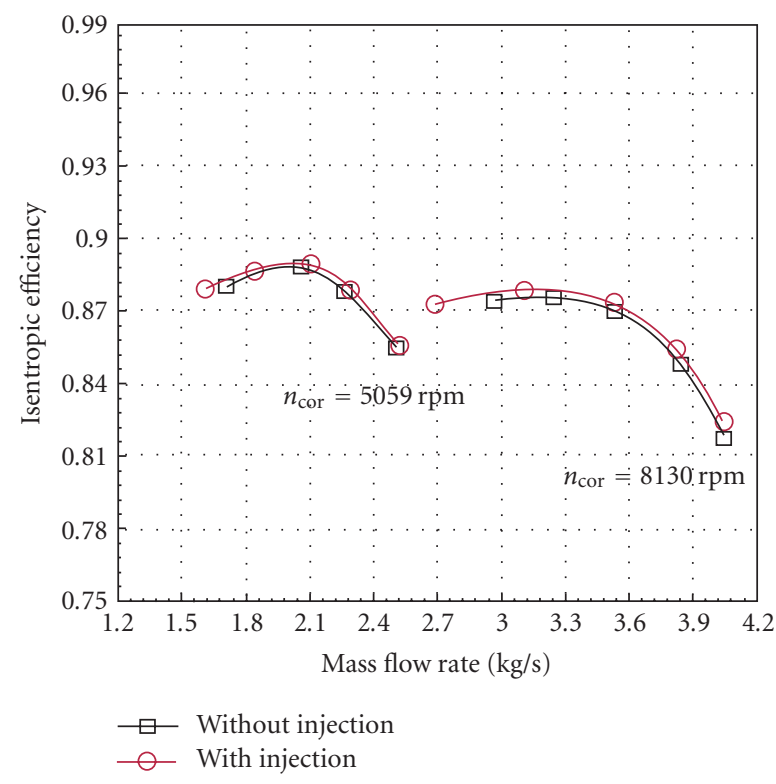

(b) Isentropic efficiency

FIGURE 6: Comparison of measured rotor performance at two different speeds with and without steady micro-air injection.

without degrading the total pressure ratio. However, in the present effort, the injected flow is supplied from an external source, but this flow should be bled from the rear of the compressor in actual application, so the efficiency penalty incurred by extracting bleed air for injection and reinjection at the upstream of the rotor may offset any efficiency benefit to the compressor. The measured extension of operating range for the isolated rotor was about 7.69 percent at 53 percent of the design rotating speed. The extension of operating range at 33 percent of the design rotating speed was less than what was achieved at 53 percent of the design speed, but was still noticeable.

\section{NUMERICAL RESULTS AND DISCUSSION}

In order to provide insight into how steady micro-tip injection increases the rotor stability, the flow in the compressor rotor with and without injection was studied numerically. Figure 7 shows the predicted rotor performance at the 53percent design rotating speed with and without the tip injection compared to experimentally obtained data. Overall performance measurements are reported in terms of totalto-static pressure ratio, which is defined as the area-averaged rotor exit static pressure divided by mass-averaged rotor inlet stagnation pressure. Due to their physical nature, these averages were thus used to reduce the three-dimensional pressure ratio of the passage into a one-dimensional pressure ratio characteristic required to infer stall inception type. In order to accurately capture the near-stall point, the increase of the compressor's back pressure is reduced to the lowest level. The predicted "near-stall point" was judged to be the last stable condition prior to incurring a numerical stall. Here, the same criteria (a divergent solution behavior or a continual dropping in mass flow rate with increasing iteration count) were applied to determine numerical stall in the computation with injection or without injection. To understand changes in the flow structure during the stall process, an unsteady calculation was performed for the case without tip injection by incrementally increasing the reference's back pressure. $\mathrm{Nu}-$ merical stall in the unsteady simulation was characterized by a consistently dropping mass flow rate. An instantaneous solution from this calculation marked as "in stall" is also shown in Figure 7 as an in-stall condition. It can be seen from Figure 7 that the calculated compressor rotor characteristic and flow range agree fairly well with the experimental data and the simulations are able to predict the position of the stall limit within an accuracy of less than 1 percent. Therefore, it can be concluded that the numerical model used is able to reveal the important flow mechanisms which are essential for understanding the influence of steady micro-tip injection. In addition, the negative slope of the pressure ratio characteristic at the equilibrium solution limit (Figure 7(a)) thus associated this case with spike stall inception.

To understand the mechanisms of the steady micro-air injection with regard to the stall margin extension, it is useful at first to understand the mechanism of stall for the compressor rotor without tip injection. Figure 8 is a typical stalling pattern of the compressor captured by a circumferential array of seven pressure transducers $100 \%$ axial chord ahead of the rotor's leading edge. The signal was lowpass filtered to minimize phase errors, and an offset has been added to the ordinate for all traces except the bottom one to allow them to be viewed together. Clearly the compressor has a spiketype stall inception. Rotating stall develops over 1 to 2 rotor resolutions and the rotating stall cell rotates at about $67 \%$ of the rotor speed. 


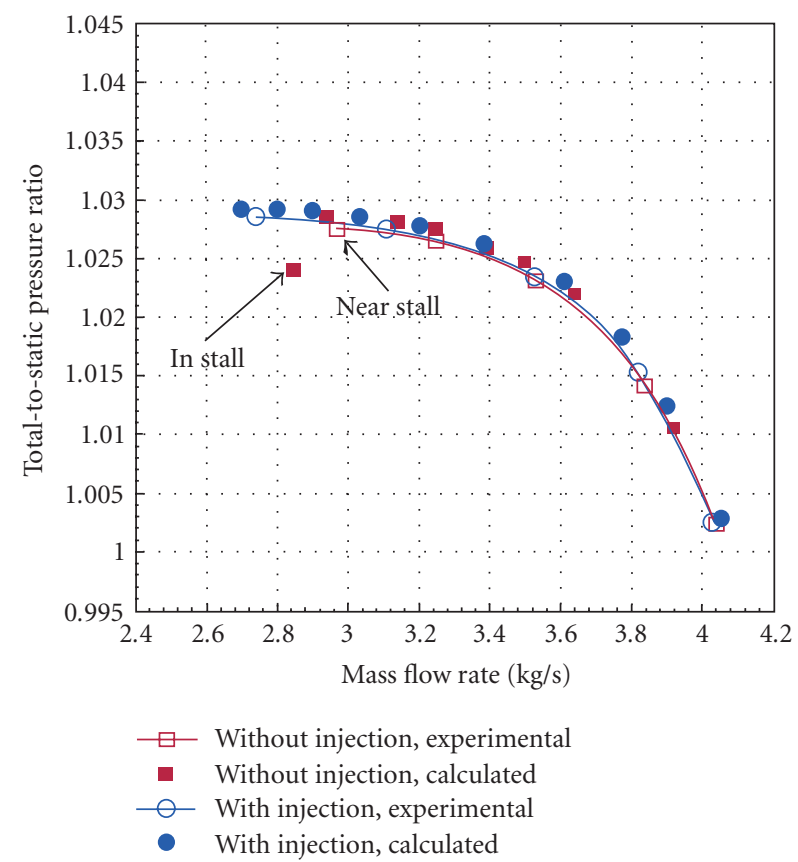

(a) Total-to-static pressure ratio

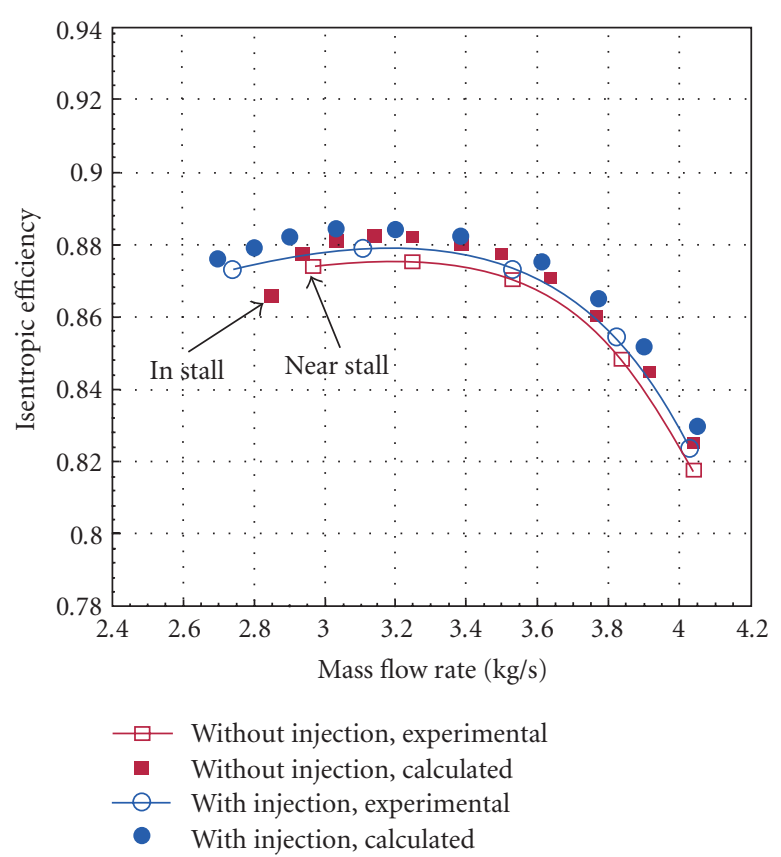

(b) Isentropic efficiency

FigURE 7: Tested and computed compressor map for 71\% design speed.

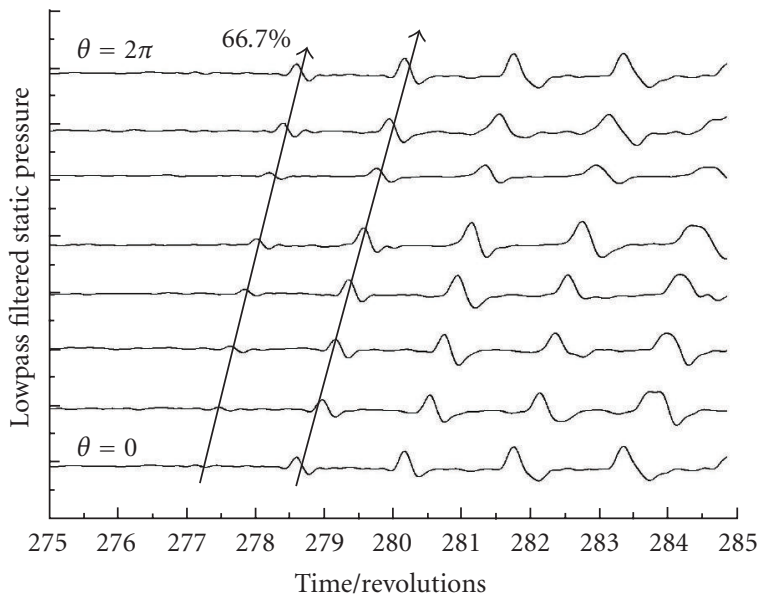

FIGURE 8: Stalling pattern of research compressor.

To examine changes in flow structure during stall, an instantaneous flow field was calculated after stall and was compared with the near-stall solution. Figures 9-11 show relative Mach number contours (99\% blade span), particle traces, and velocity vectors at the trailing edge plane (99\% blade span) at these two operating conditions. The flow features of interest are marked with blue circles. As the rotor is throttled towards stall, a significant shift of the tip-leakage vortex in the upstream direction is observed and the trajectory of the clearance vortex across the blade passage becomes more tangential. At the near-stall condition, the trajectory of the incoming/tip-clearance flow interface (high Mach number gradient) lines up with the rotor's leading edge plane at the rotor blade tip, and no forward spillage of tip-clearance flow is observed near the leading edge of rotor blade. At install condition, however, the incoming/tip-clearance flow interface is completely detached (Figure 9(b)) and the particle traces show forward spillage of tip-clearance flow just below the tip section (Figure 10(b)). Also, velocity vectors show reversed tip-clearance flow at the trailing edge plane (Figure 11(b)). Thus, the two criteria for spike-type rotating stall inception proposed by Vo et al. [16] applied to the current subsonic compressor rotor. The main mechanisms behind these stall criteria are the formation and forward movement of the low-momentum fluid, which is connected with tip-leakage vortex. It is generally believed that tip-leakage flow and its resulting vortex are major ingredients in spiketype rotating stall inceptions. Therefore, particular attention was given to examining the different tip-leakage flow topology with and without tip injection.

The coupled flow through the blade passage and the injector was solved using the unsteady-state simulation and then its time-mean calculated results were used to expose the interaction mechanism between the injector and the rotor's blade passage. In order to understand the physics that underpin the performance variations shown in Figure 7, the results should be compared under the same reference state. This is achieved by comparing the final predicted flow-field at the smoothwall stalling mass flow rate. Figure 12 shows contours of total pressure loss and entropy generation in 


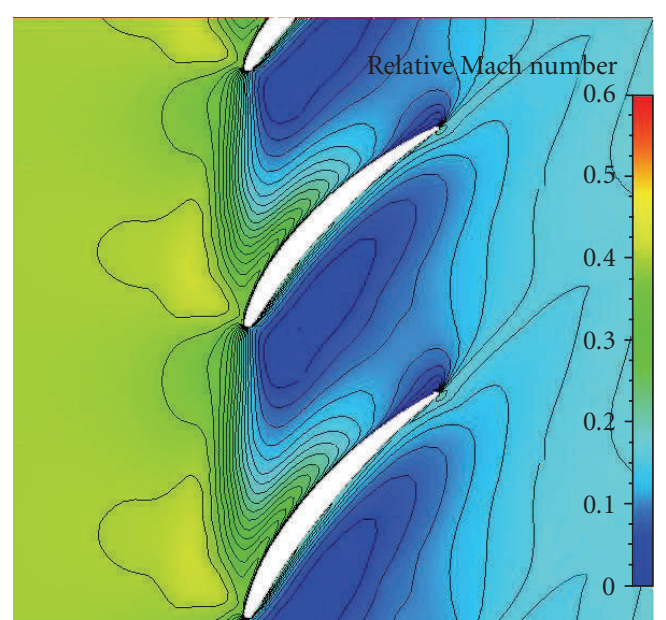

(a) Near stall

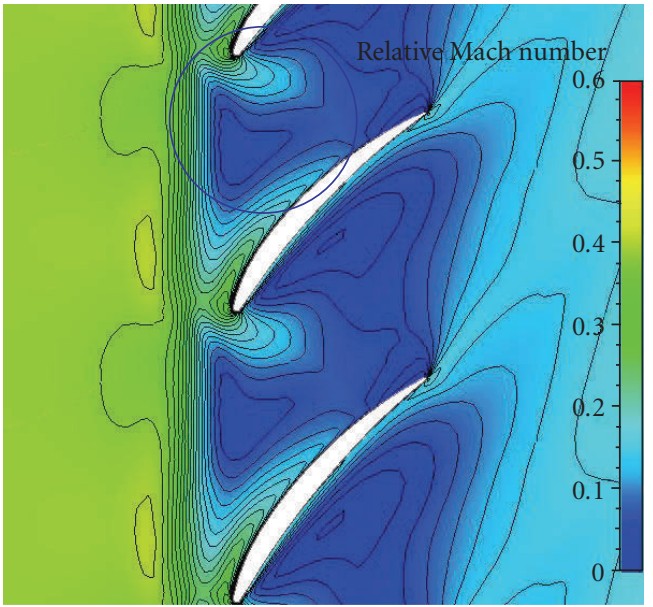

(b) In stall

FIGURE 9: Comparison of Mach number distribution (99\% blade span).

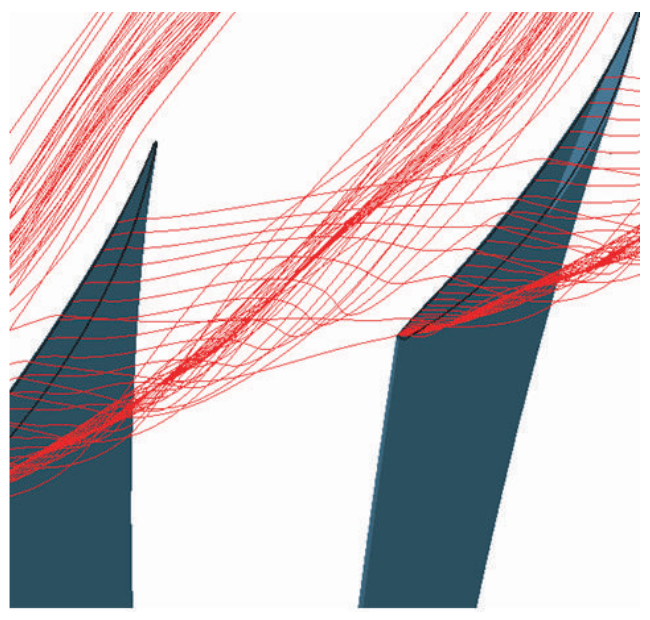

(a) Near stall

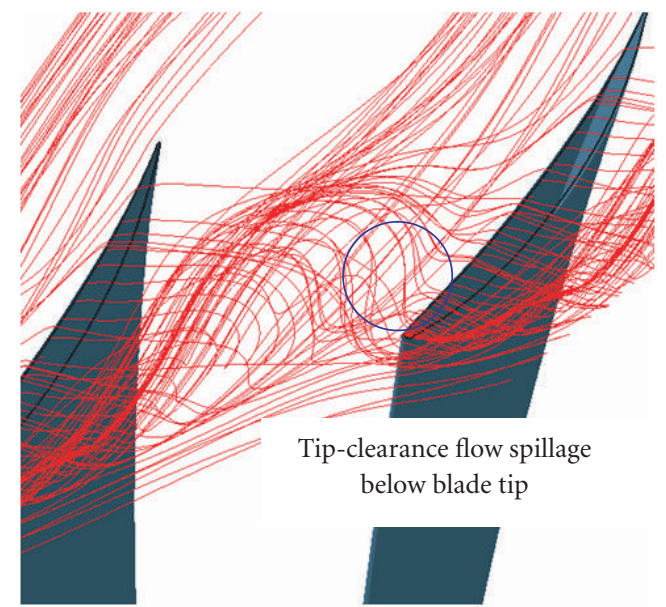

(b) In stall

Figure 10: Comparison of particle traces.

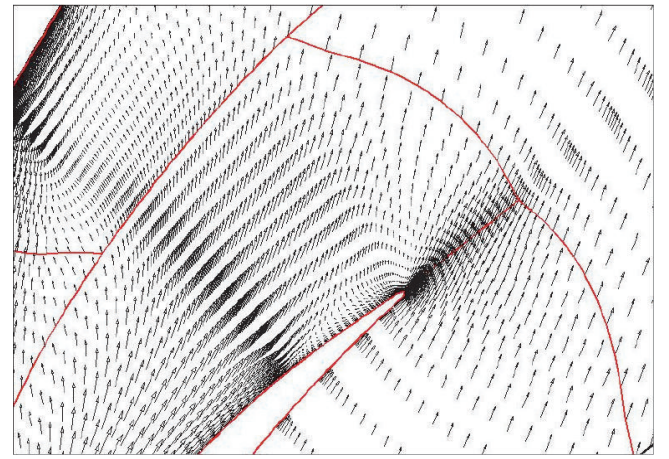

(a) Near stall

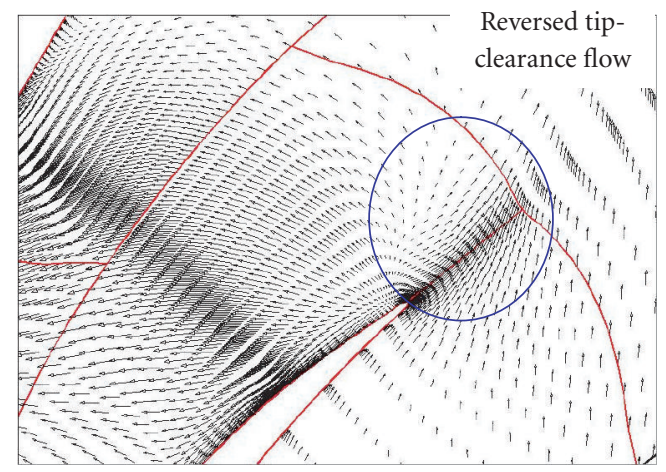

(b) In stall

FIGURE 11: Comparison of velocity vectors (99\% blade span). 


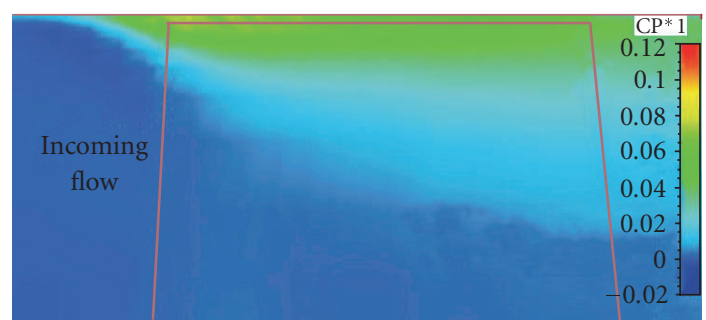

(a) Without injection

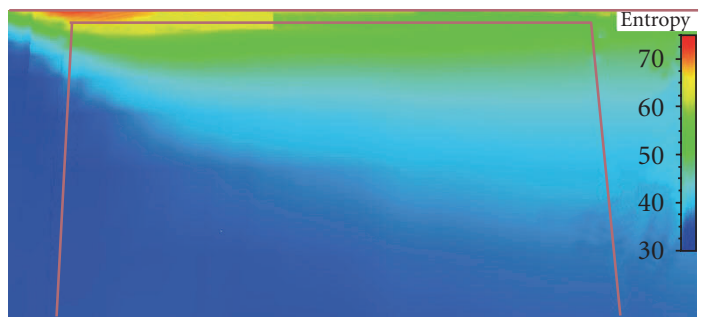

(c) Without injection

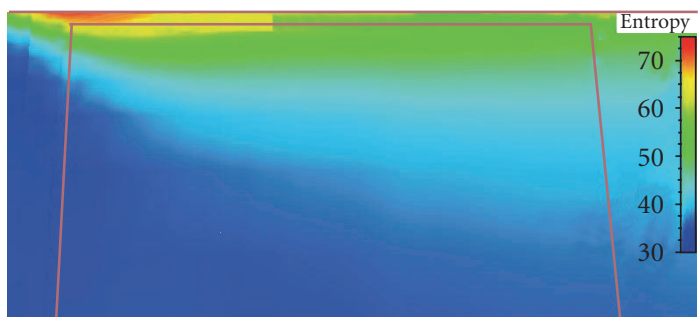

(b) With injection

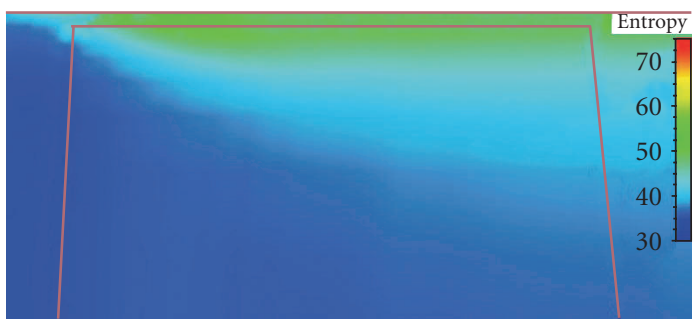

(d) With injection

FIGURE 12: Circumferentially averaged entropy and total pressure loss coefficient contours near blade tip.

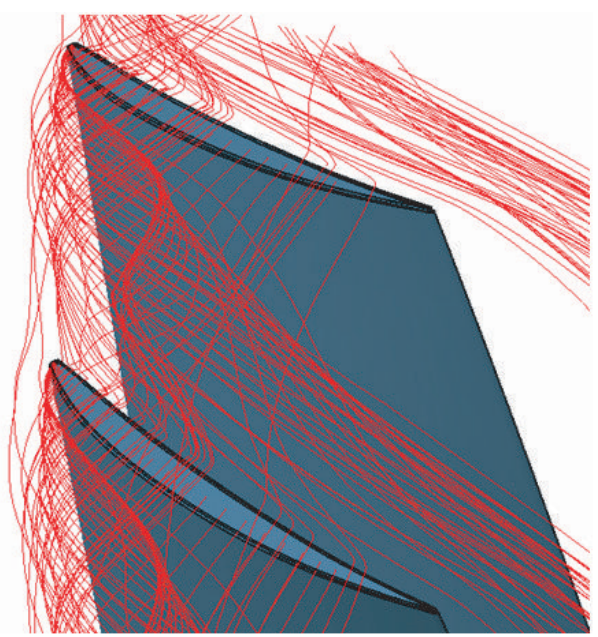

(a) Without injection

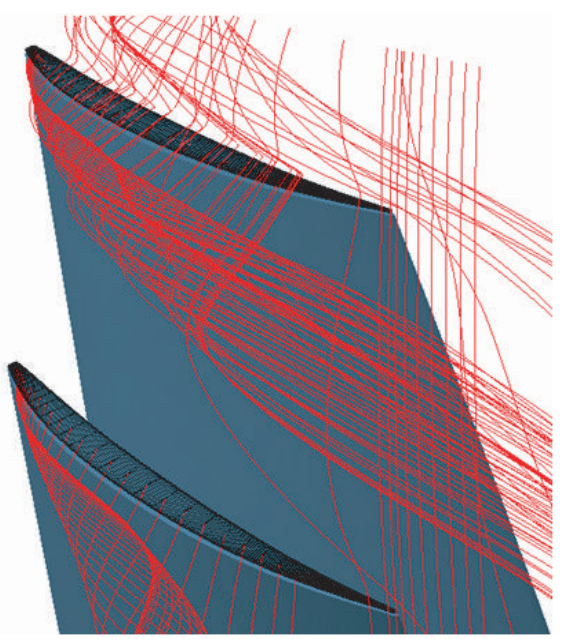

(b) With injection

FIGURE 13: Computed tip-clearance vortex particle traces at smoothwall stall mass flow rate.

meridional plane for the cases without injection and with injection. The total pressure loss was normalized by inlet total pressure and the high-loss region corresponds to the vortex core. For the case without injection, the tip-leakage vortex moves farther and farther upstream as the compressor was throttled towards stall. As the near-stall state was approached, the incoming/tip-clearance flow lined up with the rotor leading edge plane near the blade tip radius (Figure 6). Whereas for the case with injection (Figure 6), most of the high-loss fluid (blocking effect) near the tip of the rotor blade's leading edge was diminished. The tip injection is also found to be able to retard the upstream movement of the incoming/tip-clearance flow interface and forward movement of tip-clearance vortex, therefore contributes to stall margin enhancement. In addition, with injection, the overall entropy generation is lower compared to the case without tip injection. This explains the not negligible increase in compressor rotor efficiency. It is evident that the effects of tip injection are only significant in the near-blade-tip region, and as such the contour plots remain unchanged for mid-span region.

Particle traces of the tip-clearance vortex, both with and without injection, are compared in Figure 13. The tip vortex traces are formed by releasing particles from the region about 


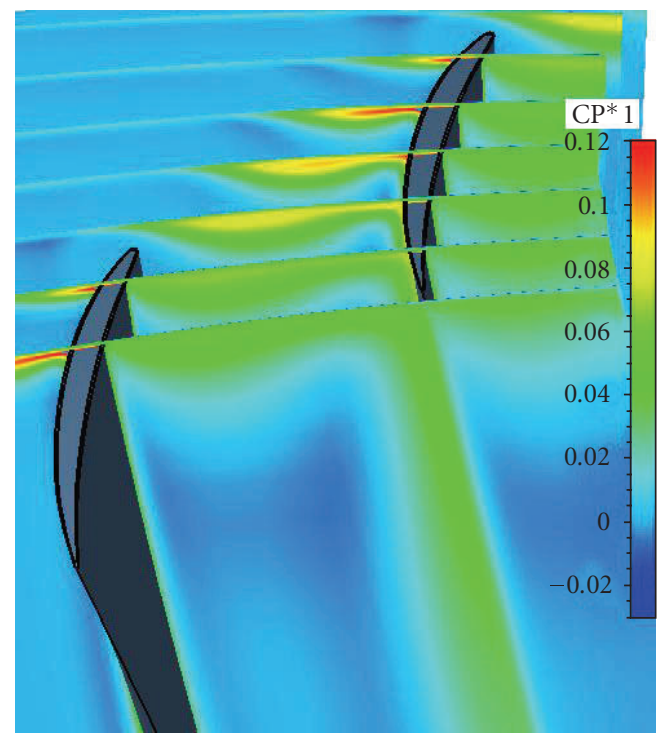

(a) Without injection

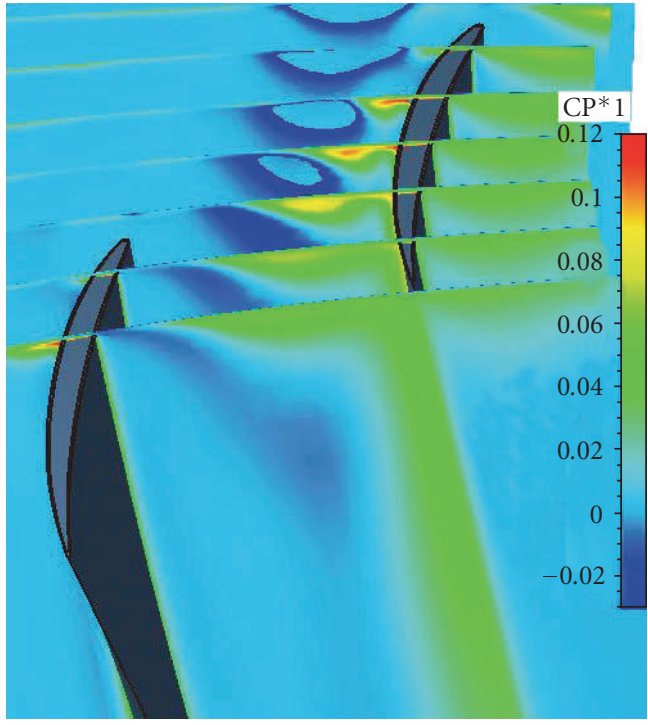

(b) With injection

Figure 14: Total pressure loss coefficient distributions on cross-flow planes for smoothwall stall mass flow rate.

$1 \%$ chord downstream of the leading edge and 50\% normalized tip clearance above the blade tip. From these figures, it is apparent that there are drastic differences for the cases without injection and with injection and the resultant effect on tip-clearance flow trajectories. Without injection, the tipleakage vortex emanates from the vicinity of the blade's leading edge and extends towards downstream pressure side of the adjacent rotor blade. However, with injection, the tipleakage vortex does not emanate from the vicinity of the blade's leading edge, instead, the tip-leakage vortex is observed to stem from farther aft than is the case without tip injection. In other words, the location of the tip-leakage vortex with injection is now shifted further downstream. The effect of steady micro-air injection appears to be that of sweeping the tip-clearance flow farther aft than that which occurs in the case without injection. This eliminates much of the blockage associated with the clearance flow in the forward part of the blade passage. Therefore, as stall inception is accompanied by the tip-clearance vortex moving forward, the effect of steady micro-air injection in delaying this phenomenon could be anticipated. In addition, the spread of the tip-leakage flow perpendicular to the blade chord is reduced.

Evidences supporting the predicted performance improvements are further provided in Figure 14. Figure 14 shows the contours of relative total pressure loss in several selected planes nearly normal to the rotor tip chord direction. As shown in Figure 14(a), without tip injection, the high-loss region accumulates around the leakage vortex core and grows larger gradually in the streamline direction. When approaching the exit of the passage, the vortex loss core occupies almost the full blade pitch. Since the radial growth of the vortex loss core is not that strong, the loss region changes its shape from circular to oval when passing through the passage. A significant radial immersion of the vortex loss region of about $8 \%$ blade height can be observed at the exit of the rotor. However, with tip injection the extent of low relative total pressure flow accumulating near the casing endwall is significantly reduced. Caused by the above-mentioned mechanism, the vortex loss core was deflected towards the suction surface and takes a more streamwise orientation. This is consistent with the previous observation of the three-dimensional structure of the tip-leakage vortex. At the exit of the rotor, the loss region covers a smaller portion of the blade pitch and gives less blockage due to reduced growth and interaction of the tip vortex with the main flow than in the case of without tip injection being employed.

Figure 15 shows the instantaneous distribution of relative Mach number at different time instants during one injector passing period $T$ in order to provide some qualitative insight into aerodynamic interaction between injector and tip-leakage flow from an unsteady point of view. Depending on the relative position between the injector and blade passage, the trajectory of tip-clearance vortex is different. As the mass flow rate decreases, the incoming/tipclearance flow interface moves towards the leading edge and this interface lines up with the rotor leading edge plane near the blade tip radius as the near-stall state was approached. As the injector approaches the rotor blade passage, the high-speed injected flow can retard upstream movement of incoming/tip-clearance flow interface and have a beneficial effect on the flow range of compressor. However, as the injector is far away from the rotor blade passage at some moment, the incoming/tip-clearance flow interface moves towards the leading edge but the high-energy injected 


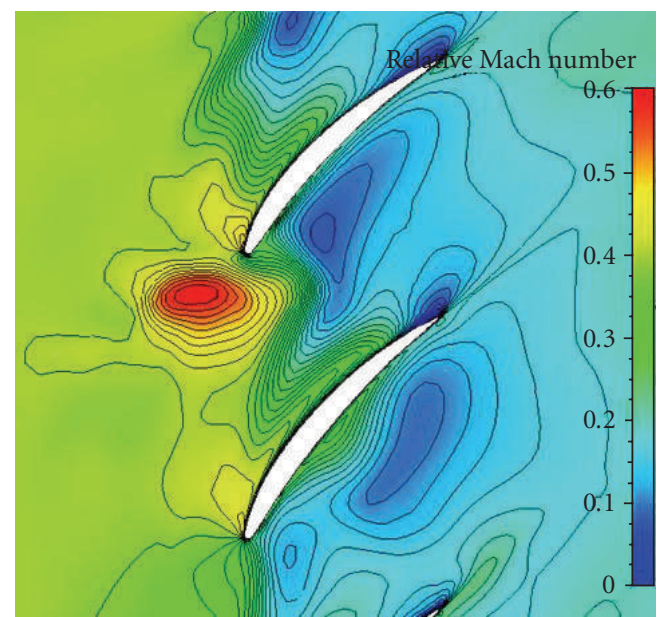

(a) $t=T / 4$

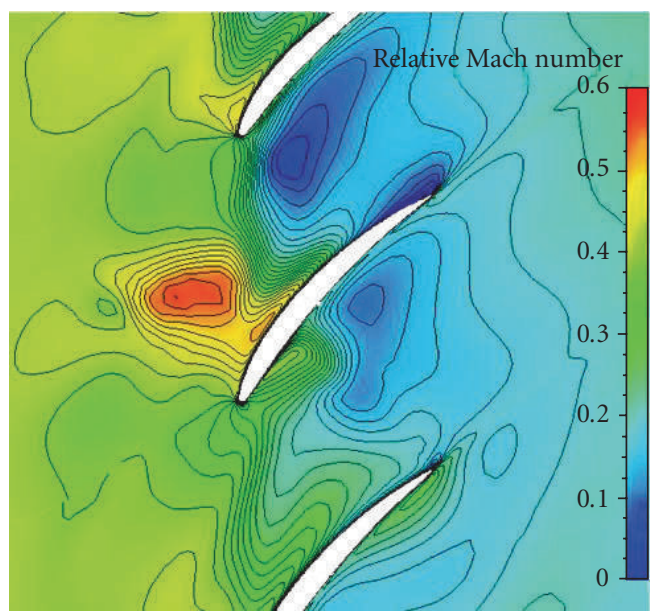

(c) $t=3 T / 4$

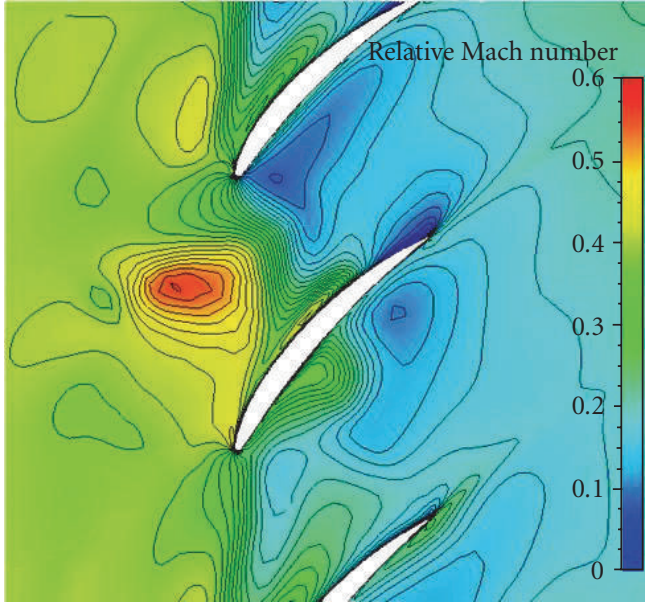

(b) $t=2 T / 4$

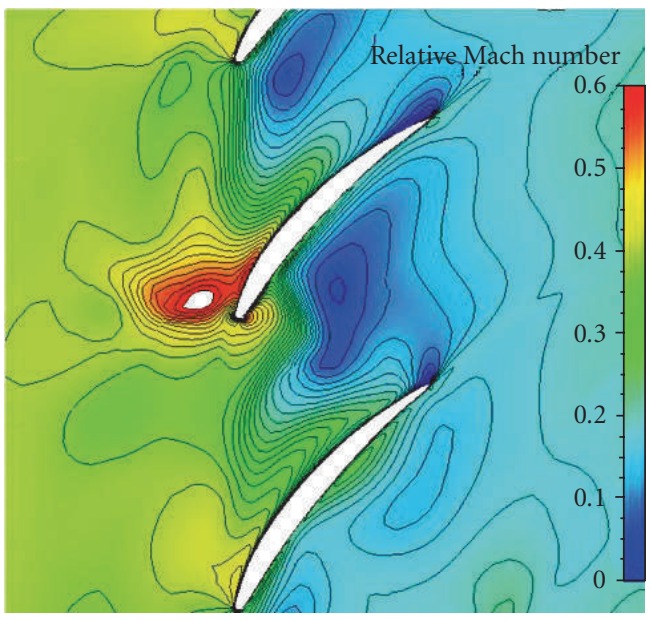

(d) $t=4 \mathrm{~T} / 4$

FIgURE 15: Distribution of relative Mach number at 99\% blade span for different instants during one injector passing period.

flow approaches the rotor blade passage again, and this process is repeated (once the blade has progressed to the point where the blade suction is exposed to the slot opening, a strong, jet-like flow injection is initiated and the cycle is renewed with the advancement of the next rotor airfoil). Because 4 injectors are symmetrically distributed around the compressor annulus, the frequency of interaction between the incoming/tip-clearance flow interface and the injected flow is $542 \mathrm{~Hz}$.

\section{CONCLUSIONS}

A state-of-the-art design for the tip injection through the casing with flush-mounted inclined holes for extending the operating range of a modern subsonic axial-flow rotor has been developed. The effect of steady micro-air injection on the compressor's performance and its mechanisms with regard to the stall margin extension were investigated with the help of a subsonic compressor test rig and NUMECA software. The following conclusions can be drawn from this investigation.

(1) Steady micro-air injection has the potential to significantly extend the operating range of the compressor with minimal or no loss in isentropic efficiency. Experimental results demonstrate that at 53\% design speed, the stalling mass flow can be reduced by $7.69 \%$ using an injected mass flow equivalent to $0.064 \%$ of the annulus flow.

(2) The unsteady simulation of the coupled flow through the rotor blade passage and injector offered a valuable insight into the fundamental physics of the steady tip injection stall delaying action. The details of the flow visualization at the tip have exposed the different tip flow topologies between the cases with injection and without injection. For the case without 
injection, the tip-leakage vortex moved farther and farther upstream and the trajectory of the incoming/tipclearance flow interface lines up with the rotor's leading edge plane at the blade tip as the near-stall state was approached. The physical mechanisms responsible for extending the compressor stall margin afforded by the steady micro-tip injection are linked to retarding upstream movement of incoming/tip-clearance flow interface and delaying the inception of stall.

(3) Encouraged by the results reported herein, the identification of design criteria, which are particularly advantageous to manipulate the tip-leakage flow and its resulting vortex, will be the focus of future work. Investigations will concentrate on parametric investigation of the impact of varying injection angles and injection mass flow rates on the stability and performance of the compressor rotor in order to find the optimum injection configuration that gives maximum operating enhancements with the least amount of external air supply.

\section{ACKNOWLEDGMENT}

This research in funded by the Doctorate Foundation of Northwestern Polytechnical University (CX200512), this support is gratefully acknowledged.

\section{REFERENCES}

[1] I. Wilke and H.-P. Kau, "A numerical investigation of the influence of casing treatments on the tip leakage flow in a HPC front stage," ASME paper 2002-GT-30642, 2002.

[2] D. C. Rabe and C. Hah, "Application of casing circumferential grooves for improved stall margin in a transonic sxial compressor," ASME paper 2002-GT-30641, 2002.

[3] H. Fujita and H. Takata, "Study on configurations of casing treatment for axial flow compressors," Bulletin of the Japanese Society of Mechanical Engineers, vol. 27, no. 230, pp. 16751681, 1984.

[4] X. Lu, J. Zhu, W. Chu, and Y. Wu, "Mechanism of the interaction between casing treatment and tip leakage flow in a subsonic axial compressor," ASME paper 2006-GT-90077.

[5] H. J. Weigl, J. D. Paduano, L. G. Fréchette, et al., "Active stabilization of rotating stall and surge in a transonic single-stage axial compressor," Journal of Turbomachinery, vol. 120, no. 4, pp. 625-636, 1998.

[6] Z. S. Spakovszky, H. J. Weigl, J. D. Paduano, C. M. Van Schalkwyk, K. L. Suder, and M. M. Bright, "Rotating stall control in a high-speed stage with inlet distortion: part I-radial distortion," Journal of Turbomachinery, vol. 121, no. 3, pp. 510-516, 1999.

[7] Z. S. Spakovszky, C. M. Van Schalkwyk, H. J. Weigl, J. D. Paduano, K. L. Suder, and M. M. Bright, "Rotating stall control in a high-speed stage with inlet distortion: part II-circumferential distortion," Journal of Turbomachinery, vol. 121, no. 3, pp. 517-524, 1999.

[8] K. L. Suder, M. D. Hathaway, S. A. Thorp, A. J. Strazisar, and M. B. Bright, "Compressor stability enhancement using discrete tip injection," Journal of Turbomachinery, vol. 123, no. 1, pp. 14-23, 2001.
[9] X. Lu, J. Zhu, and W. Chu, "Numerical and experimental investigation of stepped tip gap effects on a subsonic axial-flow compressor rotor," Proceedings of the Institution of Mechanical Engineers, Part A: Journal of Power and Energy, vol. 219, no. 8, pp. 605-616, 2005.

[10] C. Nie, G. Xu, X. Cheng, and J. Chen, "Micro air injection and its unsteady response in a low-speed axial compressor," ASME paper 2002-GT-30361.

[11] C. Sheng and M. Remotigue, "Numerical simulation of rotor 35 with and without tip injection using an arbitrary mach number flow solver," AIAA paper 2004-372, 2004.

[12] B. H. Beheshti, J. A. Teixeira, P. C. Ivey, B. Farhanieh, and K. Ghorbanian, "A new design for tip injection in transonic axial compressors," ASME paper 2006-GT-90007, 2006.

[13] X. Lu, W. Chu, J. Zhu, and Y. Wu, "Experimental and numerical investigation of a sunsonic compressor with bend skewed slot casing treatment," ASME paper 2006-GT-90026.

[14] NUMECA's flow integrated environment for turbomachinery and internal flows, User Manual Version 6.1-1, April 2003.

[15] A. J. Strazisar, M. M. Bright, S. Thorp, D. E. Culley, and K. L. Suder, "Compressor stall control through endwall recirculation,” ASME paper 2004-GT-54295, 2004.

[16] H. D. Vo, C. S. Tan, and E. M. Greitzer, "Criteria for spike initiated rotating stall,” ASME Paper 2005-GT-68374, 2005. 

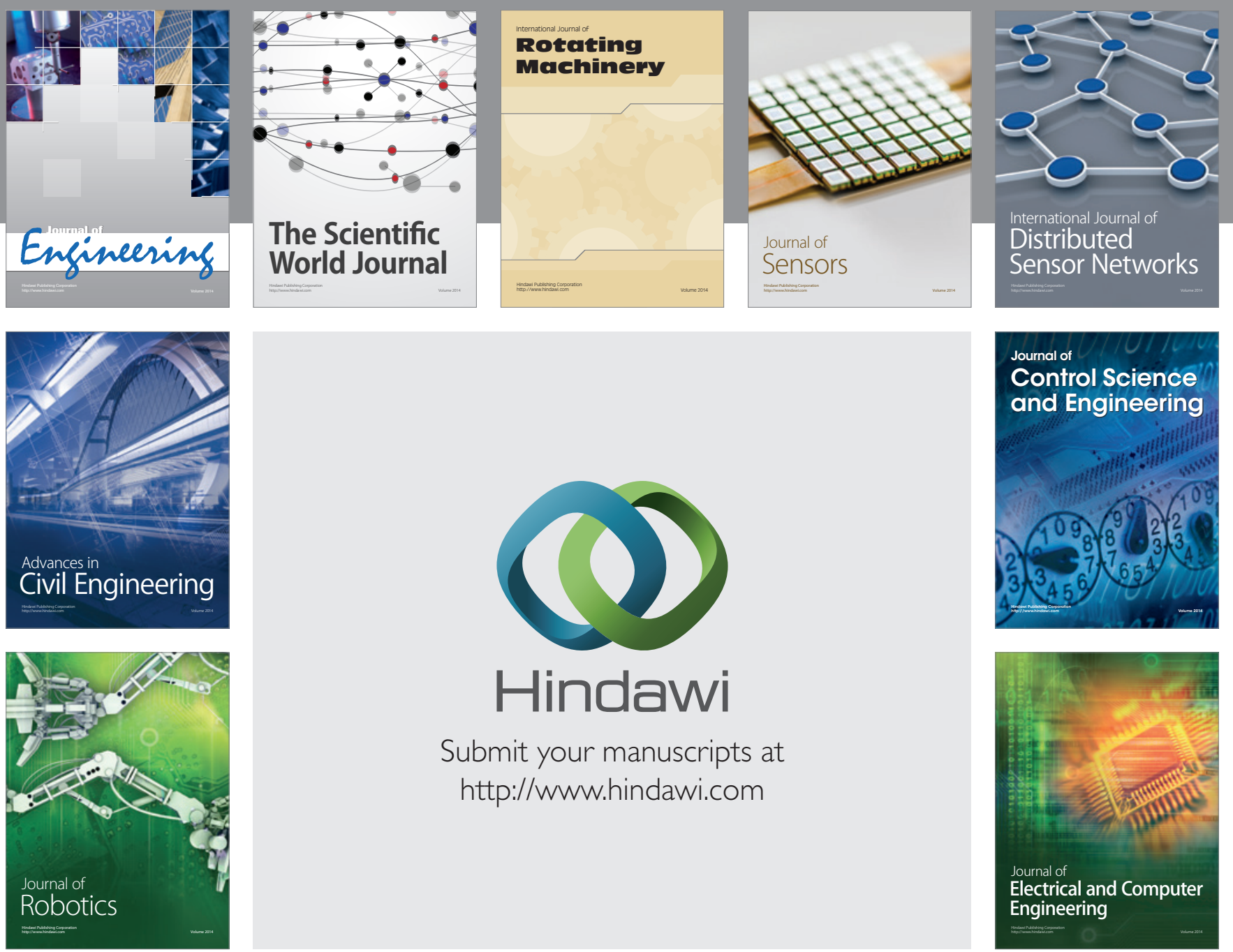

Submit your manuscripts at

http://www.hindawi.com
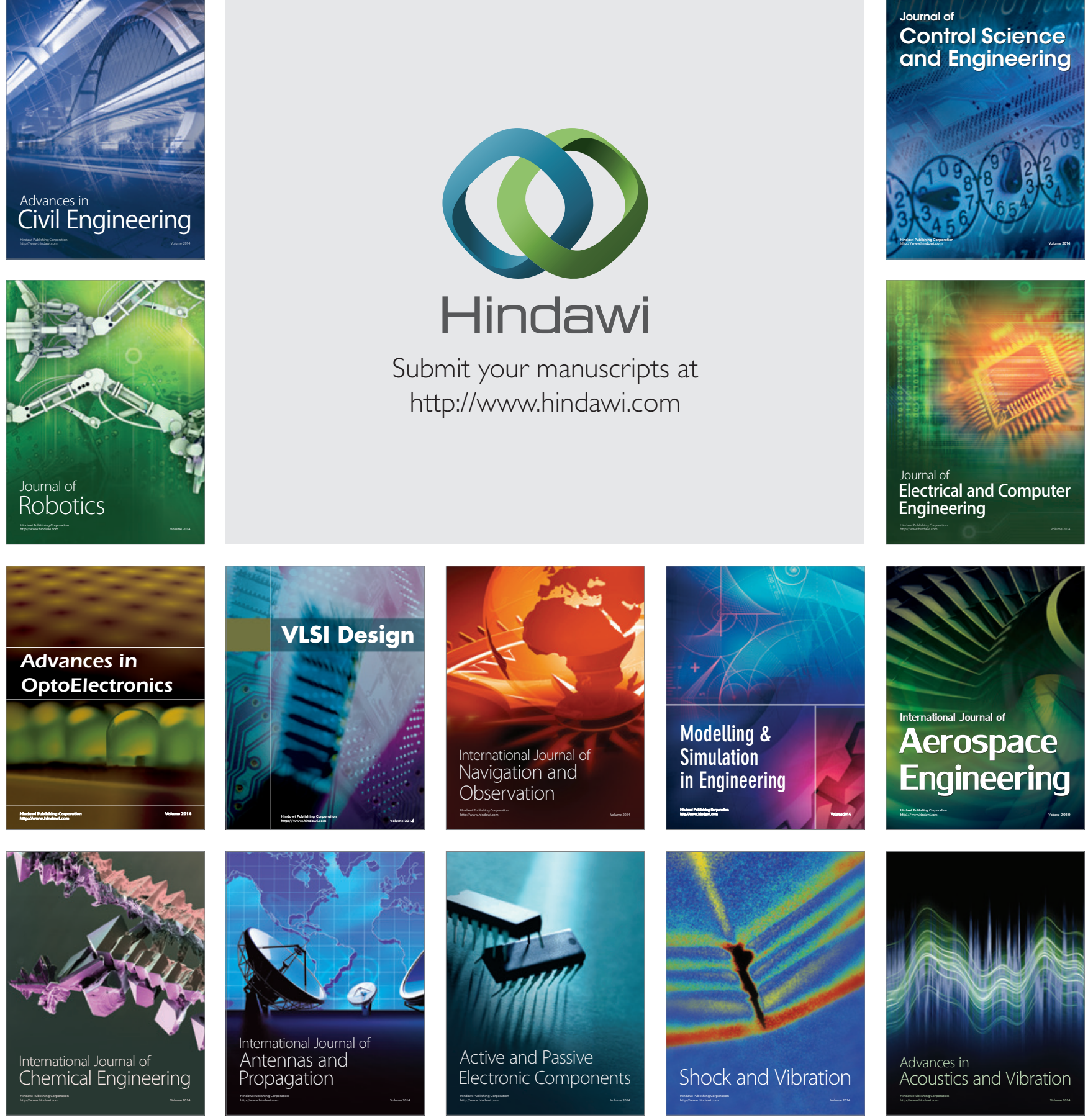